\title{
Kangaroo mother care: a multi-country analysis of health system bottlenecks and potential solutions
}

\author{
Linda Vesel ${ }^{1,2^{*}}$, Anne-Marie Bergh ${ }^{3}$, Kate J Kerber ${ }^{4}$, Bina Valsangkar ${ }^{4}$, Goldy Mazia ${ }^{5}$, Sarah G Moxon ${ }^{4,6,7}$, \\ Hannah Blencowe ${ }^{4,6,7}$, Gary L Darmstadt ${ }^{8}$, Joseph de Graft Johnson ${ }^{4,5}$, Kim E Dickson ${ }^{2}$, \\ Juan Gabriel Ruiz Peláez ${ }^{9,10,11}$, Severin Ritter von Xylander ${ }^{12}$, Joy E Lawn ${ }^{4,6,7}$, \\ On behalf of the KMC Research Acceleration Group
}

\begin{abstract}
Background: Preterm birth is now the leading cause of under-five child deaths worldwide with one million direct deaths plus approximately another million where preterm is a risk factor for neonatal deaths due to other causes. There is strong evidence that kangaroo mother care (KMC) reduces mortality among babies with birth weight $<2000 \mathrm{~g}$ (mostly preterm). KMC involves continuous skin-to-skin contact, breastfeeding support, and promotion of early hospital discharge with follow-up. The World Health Organization has endorsed KMC for stabilised newborns in health facilities in both high-income and low-resource settings. The objectives of this paper are to: (1) use a 12-country analysis to explore health system bottlenecks affecting the scale-up of KMC; (2) propose solutions to the most significant bottlenecks; and (3) outline priority actions for scale-up.

Methods: The bottleneck analysis tool was applied in 12 countries in Africa and Asia as part of the Every Newborn Action Plan process. Country workshops involved technical experts to complete the survey tool, which is designed to synthesise and grade health system "bottlenecks", factors that hinder the scale-up, of maternal-newborn intervention packages. We used quantitative and qualitative methods to analyse the bottleneck data, combined with literature review, to present priority bottlenecks and actions relevant to different health system building blocks for KMC.

Results: Marked differences were found in the perceived severity of health system bottlenecks between Asian and African countries, with the former reporting more significant or very major bottlenecks for $K M C$ with respect to all the health system building blocks. Community ownership and health financing bottlenecks were significant or very major bottlenecks for KMC in both low and high mortality contexts, particularly in South Asia. Significant bottlenecks were also reported for leadership and governance and health workforce building blocks.

Conclusions: There are at least a dozen countries worldwide with national KMC programmes, and we identify three pathways to scale: (1) champion-led; (2) project-initiated; and (3) health systems designed. The combination of all three pathways may lead to more rapid scale-up. KMC has the potential to save lives, and change the face of facility-based newborn care, whilst empowering women to care for their preterm newborns.
\end{abstract}

\section{Background}

Vulnerability of preterm and/or small for gestational age newborns

Globally, 2.8 million newborns die each year, comprising $44 \%$ of under-five child deaths [1]. Newborns in lowand middle-income countries (LMICs) contribute to

\footnotetext{
* Correspondence: linda.vesel@concern.net

'Innovations for Maternal, Newborn and Child Health, Concern Worldwide US, 355 Lexington Avenue, New York, NY 10017, USA

Full list of author information is available at the end of the article
}

98\% of this burden, with more than three-quarters of the deaths in sub-Saharan Africa and South Asia - the very regions where progress for saving newborn lives is slowest [2]. Only recently has newborn health begun to emerge as a global and national public health priority, especially through attention to child survival in the Millennium Development Goals [3], and the Born Too Soon and Every Newborn [4] movements designed to specifically accelerate action for newborns. 
Preterm birth accounts for an estimated $3.1 \%$ of all global disability-adjusted life years, directly through 1.1 million deaths and indirectly as a risk factor for many other cause-specific newborn deaths $[5,6]$. Each year, there are an estimated 15 million preterm newborns (born before 37 weeks of gestation) [7], most of whom are low birth weight (LBW) $(<2500 \mathrm{~g})$ [2]. The commonest underlying causes of LBW are prematurity, intrauterine growth restriction, or a combination of the two [2]. Africa has the highest rates of preterm birth [7] and South Asia has the highest rates of intrauterine growth restriction [2]. The time immediately after birth presents the greatest risk of death, which is exacerbated for preterm newborns as they have less physiological reserve, greater challenges with temperature regulation, immature organs (especially lungs, leading to respiratory distress syndrome), poor immune function, and heightened vulnerability to severe infections putting them at risk for problems associated with the transition to extrauterine life $[8,9]$. The outcome of a preterm baby is a sensitive test of health system function; the highest preterm-specific mortality is in Sierra Leone [2], where health system gaps have now been illuminated by Ebola but have always been present.

\section{Kangaroo mother care definition}

$\mathrm{KMC}$ is an approach to the care of preterm and/or LBW infants, which engages and empowers mothers and families as the main providers of the biological (warmth and food) and psycho-emotional (contact, caring, bonding and comfort) needs of their newborn. The cornerstone of KMC is the kangaroo position whereby the infant is placed and held in direct skin-to-skin contact on the mother's chest in an up-right position under her clothes. The aim is for early initiation of KMC and for continuous performance (over 18 hours per day), but initiation, continuity and duration may vary according to the stability of the infant and the context of care. Other key components of KMC are support for exclusive and early breastmilk provision and timely discharge from the hospital with appropriate follow-up [10]. KMC was first developed and scientifically evaluated in Colombia over three decades ago as an alternative to incubator care [10-13]. The evidence generated in Colombia allowed authorities to gradually include KMC in national LBW guidelines and spread the practice to a large number of health facilities. Recently, with preterm birth becoming the leading cause of under-five mortality, and additional evidence on KMC's mortality benefit, more attention has been focused on scaling up the practice.

Meta-analyses show that KMC reduces neonatal mortality, halving deaths among LBW babies weighing $<2000 \mathrm{~g}[14,15]$. KMC has multiple other benefits, including reductions in infection and sepsis by nearly
$60 \%[2,15,16]$, as well as reductions in hypothermia and lower respiratory tract disease, and improved duration of exclusive breastfeeding, weight gain, length and head circumference, maternal-infant bonding and long-term child development and health [10,14-21]. Intermittent KMC may also be beneficial, especially to non-mortality outcomes (higher rates of breastfeeding, better shortterm physiological regulation, maternal bonding, amongst others), but as yet there are limited data.

KMC has been formally endorsed by the World Health Organization (WHO) for stabilised babies $<2000$ $\mathrm{g}$ in health facilities as a safe complement to conventional neonatal care $[22,23]$. The evidence to date is for facility implementation of KMC and continuation at home post-discharge, and as yet community-based initiation of KMC is not recommended. Figure 1 shows how skin-to-skin care and KMC can be integrated within the health system, but this may look different in different health system contexts and levels of care. KMC is a cornerstone of facility-based care for small and sick babies, and can complement neonatal intensive care of extremely premature babies. KMC is embedded in the broader continuum of care for small and sick newborns, including obstetric care [24], management of preterm labour [25], basic newborn care and resuscitation [26], management of infections [27] and more comprehensive care of small and sick newborns, especially those with respiratory complications [28].

The distinction between KMC and skin-to-skin care should be clear. Skin-to-skin care for term newborns where babies are placed on their mothers chest directly after birth as part of basic newborn care [26] and intermittently thereafter - helps to promote warmth, bonding and breastfeeding as part of a continuum of woman and baby-centred care. KMC is intended for infants $<2000 \mathrm{~g}$ with the aim of thermal regulation achieved through continuous skin-to-skin contact in the KMC position. KMC may be required for weeks and is carried out alongside other aspects of care for the preterm baby.

Now, $44 \%$ of the 75 Countdown to 2015 countries report that they have a national policy on KMC in facilities for LBW/preterm newborns [3]. In many cases, these policies are recent and implementation is limited. Countries may initiate KMC and fail to increase coverage [29]. Unfortunately, coverage data are not available as yet, but are urgently needed. Hence, in-depth country analyses and case studies remain critical to learning what works and what does not.

The objectives of this paper are:

1. To use a 12-country analysis to explore health system bottlenecks affecting the scale-up of KMC. 2 . To present proposed solutions to overcome the most significant bottlenecks for KMC based on 


\section{A}

Neonatal intensive care

Intermittent KMC as tolerated

for babies requiring ventilatory support

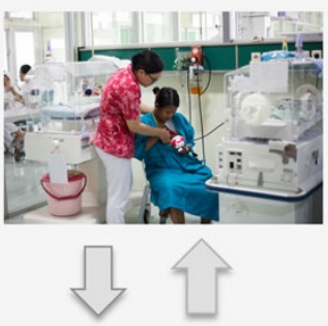

Intermediate or special care

Predominant KMC as tolerated for occasionally unstable babies
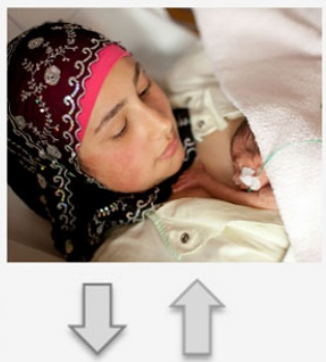

Basic preterm care Prolonged, continuous KMC for stable babies
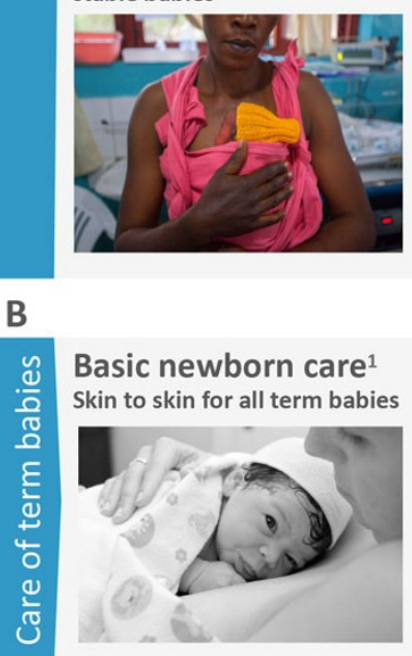

\section{Basic newborn care ${ }^{1}$}

Skin to skin for all term babies

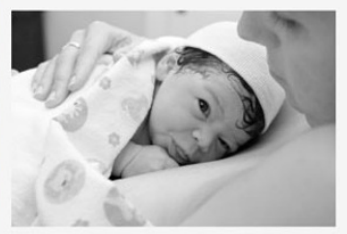

- A special ward that includes neonatal care facilities

- Incubators, resuscitaires

Place. Space for KMC and supporting breastfeeding, including reclining chairs for mothers

- Nurses with specialised neonatal skills

People - High nurse-newborn ratio e.g. 1:1 in the United Kingdom

- At least one doctor with specialised neonatal training

Equipment - Availability of Continuous Positive Airway Pressure, Intermittent Positive and Pressure ventilation and monitoring equipment

commodities - Surfactant therapy for extremely premature newborns

- 24 hour laboratory services

- Multi-disciplinary support team (e.g. nutritionist)

Support system - Long term follow up and developmental screening (e.g. occupational, speech

physical therapy)

- Space for mother and family to stay close to the baby

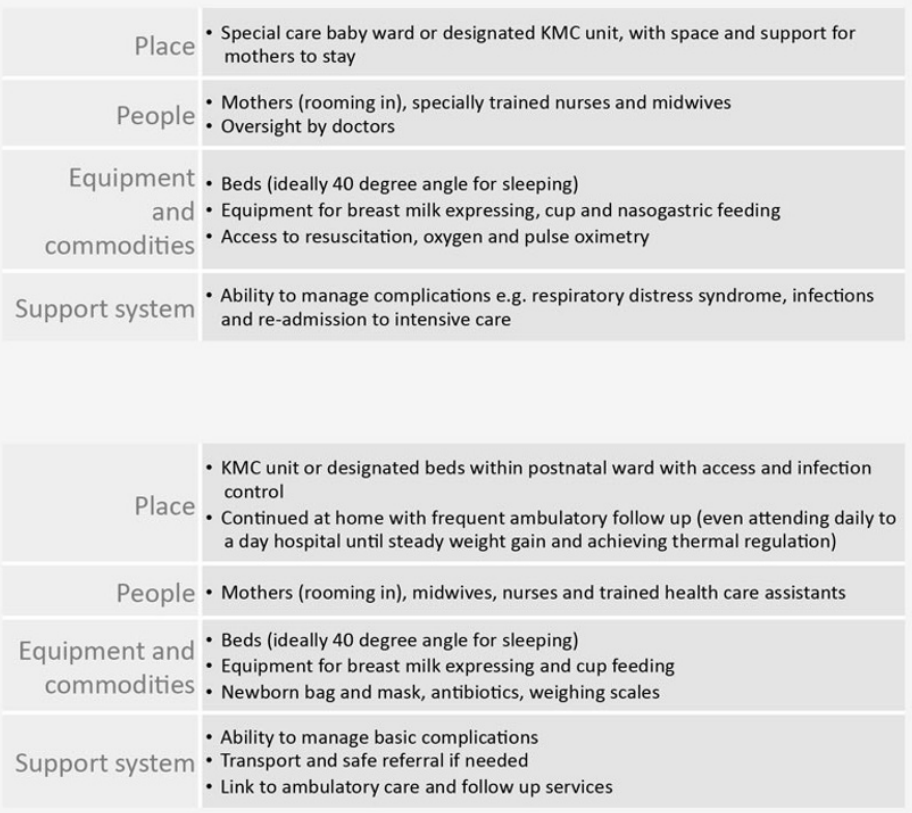

Link to ambulatory care and follow up services

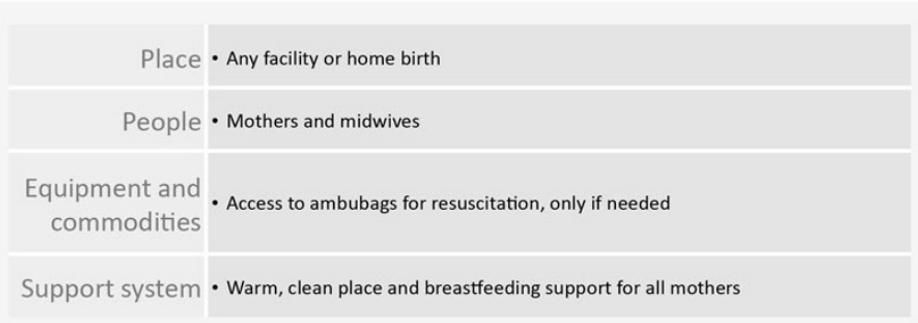

Figure 1 Kangaroo Mother Care, showing health systems requirements by level of care. Any items available at the basic level should be available at the higher level. For more details of special care and neonatal intensive care requirements see Moxon et al. paper on inpatient care of small and sick newborns in this supplement. KMC: Kangaroo Mother Care. Part A: Kangaroo mother care for preterm babies. Part B: Care of term babies. 'KMC is not the same as skin-to-skin care alone. KMC involves continuous prolonged skin-to-skin contact with the infant placed on top of the mother's chest in a prone vertical position (Kangaroo Position), support for breastmilk feeding and a supportive environment. Neonatal intensive care image source: Syane Luntungan/Jhpiego. Intermediate or special care image source: ${ }^{\circ} \mathrm{EFCNI}$. Basic preterm care image source: Save the Children. Basic newborn care image source: Joyce Godwin. 
learning from the 12-country analysis, a literature review and programme experience.

3. To discuss policy and programmatic implications and propose priority actions for KMC scale-up.

\section{Methods}

This study used quantitative and qualitative research methods to collect and assess health system bottlenecks and solutions to the scale-up of maternal and newborn care interventions in 12 countries: Afghanistan, Bangladesh, Cameroon, Democratic Republic of Congo (DRC), India, Kenya, Malawi, Nigeria, Nepal, Pakistan, Uganda, and Vietnam.

\section{Data collection}

As part of the development of the Every Newborn Action Plan (ENAP), the bottleneck analysis tool was developed to assist countries in identifying context-specific bottlenecks to the scale-up and provision of maternal and newborn health interventions across the seven WHO health system building blocks (see Additional file 1) [30,31]. The tool was applied during a series of national consultations between July $1^{\text {st }}$ and December $31^{\text {st }}, 2013$. The workshops for each country included participants from national ministries of health, United Nations agencies, the private sector, non-governmental organisations, professional bodies, academia, bilateral agencies and other institutions. For each workshop, a facilitator, oriented on the tool, coordinated the process and guided groups to reach consensus on the specific bottlenecks for each health system building block. This paper, fifth in the series, focuses on KMC.

In the tool, KMC was defined as a package with two main behaviours selected as tracers: (1) continuous skinto-skin care, placing and securing (usually with a cloth) a baby on a mother or other caregiver's bare chest; and (2) frequent and exclusive breastfeeding including support for small and sick babies who cannot feed directly from the breast.

\section{Data analysis methods}

We graded country-specific bottlenecks for each health system building block using one of the following options, which were derived from the bottleneck analysis tool that was completed by country teams: not a bottleneck $(=1)$, minor bottleneck $(=2)$, significant bottleneck $(=3)$, or very major bottleneck $(=4)$. We first present the grading in heat maps according to the very major or significant health system bottlenecks as reported by all 12 countries, then by mortality contexts (neonatal mortality rate $[\mathrm{NMR}]<30$ deaths per 1000 live births and NMR $\geq 30$ deaths per 1000 live births) and then by region (countries in Africa and countries in Asia)
(Figure 2). We developed a second heat map showing the specific grading of bottlenecks for each health system building block by individual country (Figure 3 ). Finally, we categorised context-specific solutions to overcome challenges to scaling up KMC identified in all countries into thematic areas linked to the specific bottlenecks (Table 1 and Table S2, additional file 2). We undertook a literature review to identify further case studies and evidence-based solutions for each defined thematic area (see Additional file 2).

For more information on methods, detailed analysis of the steps taken to analyse the intervention-specific bottlenecks and limitations, please refer to the overview paper [31].

\section{Results}

National level responses to the bottleneck analysis tool were analysed for 10 countries (Afghanistan, Bangladesh, Cameroon, Democratic Republic of Congo, Kenya, Malawi, Nigeria, Nepal, Uganda, and Vietnam). India and Pakistan undertook sub-national data collection for two states and five provinces, respectively [30]. All of the countries/subnational regions completed the KMC section regarding bottlenecks, solutions and grading with the exception of Nepal, which did not grade for the health information systems building block. Nepal was therefore removed from the sample for the quantitative grading of this building block, but included in the analysis of all the other building blocks.

Grading according to the number of countries that reported significant or very major health system bottlenecks for the scale-up of KMC is shown in Figure 2. Most countries reported significant or very major bottlenecks for health financing (10 countries), community ownership and partnership (10 countries), and health service delivery (10 countries). Health financing, and community ownership and partnership bottlenecks were significant or very major across countries overall, in both low and high mortality contexts and in the Asia region; this suggests that these two building blocks may be priorities to tackle in order to promote the scale-up of KMC.

Figure 3 breaks down the grading of health system building blocks reported for each individual country. Regional differences were reported in the perceived severity of health system bottlenecks, and, thus, the perceived feasibility of KMC scale-up. Asian countries reported very major or significant bottlenecks for all the building blocks except for one country that did not consider leadership and governance as a bottleneck. The difference between mortality contexts was less marked (Figure 2).

Significant bottlenecks also existed across other health system building blocks, particularly leadership and governance ( 9 countries) and health workforce ( 9 countries) (Figures 2 and 3). 


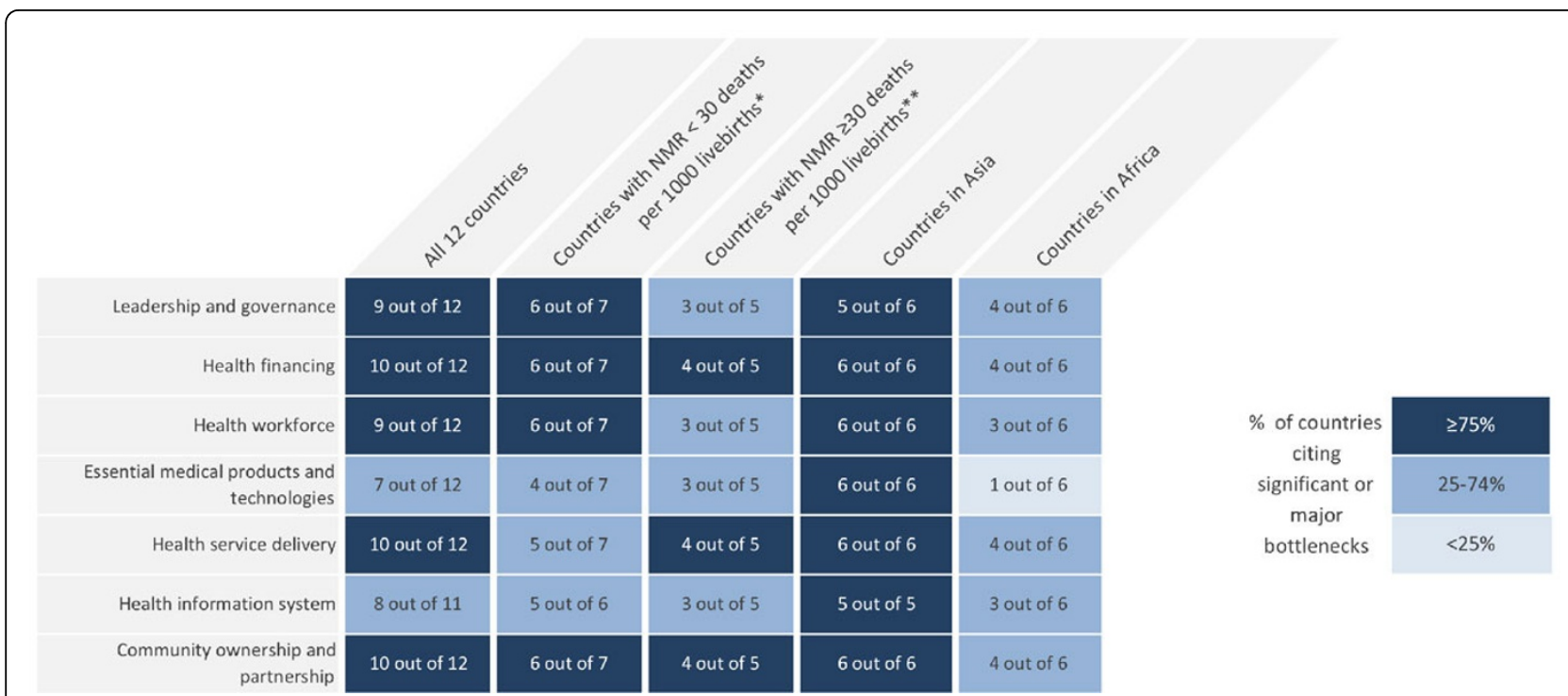

Figure 2 Very major or significant health system bottlenecks for kangaroo mother care. NMR: Neonatal mortality rate. ${ }^{*}$ Cameroon, Kenya, Malawi, Uganda, Bangladesh, Nepal, Vietnam. **Democratic Republic of Congo, Nigeria, Afghanistan, India, Pakistan. See additional file 2 for more details.

Table 1 summarises the main bottlenecks and general solution themes identified by countries for each of the seven health system building blocks, which are described below.

\section{Leadership and governance bottlenecks and solutions}

Leadership and governance was rated as having significant or very major bottlenecks across nine out of 12 countries (Figure 2). Ten out of 12 countries highlighted the absence of a national KMC policy and/or absence of the existence and dissemination of KMC service guidelines, even in facilities already promoting the practice (Table 1). Complete absence of policy and guidelines was more common in Asian countries while poor dissemination of guidelines was more common in African counties. Workshop participants reported an overall lack of prioritisation of KMC by regulatory bodies and lack of institutionalisation of KMC.

Proposed solutions to address bottlenecks centred on advocacy to increase awareness, budget and resources for $\mathrm{KMC}$; strengthening the role of the ministries of health; and sensitisation of the community and health workers to the benefits of KMC.

\section{Health financing bottlenecks and solutions}

Health financing was rated as having significant or very major bottlenecks across 10 out of 12 countries (Figure 2). Lack of finances for health at district and national levels and out-of-pocket expenses (the specific connection with KMC was not noted) were each reported as the main obstacles to the implementation and scale-up of KMC by six country teams (Table 1 ).
Proposed solutions included advocacy for increased donor support and budget for maternal and newborn health and evaluation; the development of costed master plans to support dissemination and the use of policy and guidelines; and the introduction of health finance protection schemes.

\section{Health workforce bottlenecks and solutions}

Health workforce was rated as having significant or very major bottlenecks across nine out of 12 countries: all six countries in Asia and three of six countries in Africa (Figure 2). Eight out of 12 country teams reported specific health workforce gaps affecting the uptake of KMC, including the shortage and poor distribution of welltrained health workers to care for LBW babies and support the practice of KMC (Table 1). Additional bottlenecks included lack of adequate mentorship and supervision mechanisms, and knowledge and awareness of health workers.

The most commonly proposed solution centred on improvements in training and capacity development and the creation of national newborn health training curricula that include KMC as a priority intervention. The development and implementation of job descriptions, mentoring guidelines, and supervision, monitoring and evaluation mechanisms were also mentioned.

\section{Essential medical products and technologies bottlenecks and solutions}

The essential medical products and technologies building block was rated as having significant or very major bottlenecks across seven out of 12 countries: all six countries in 
A

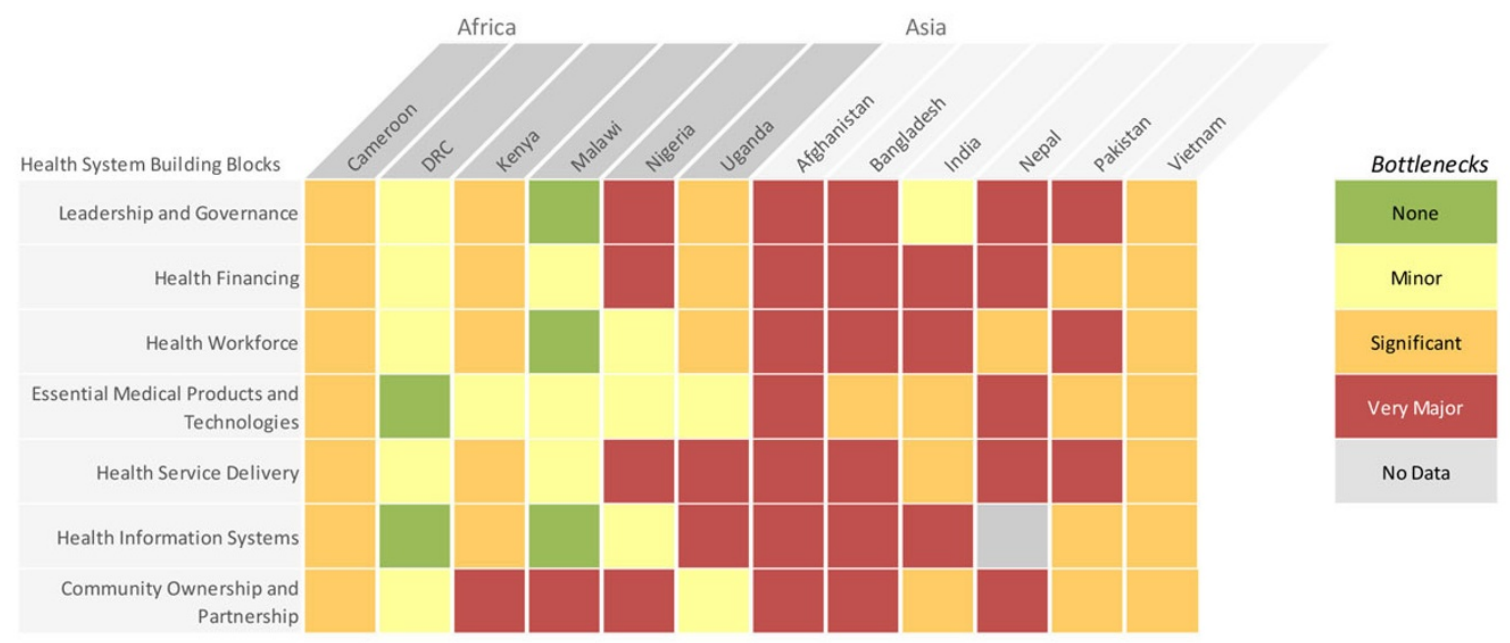

B
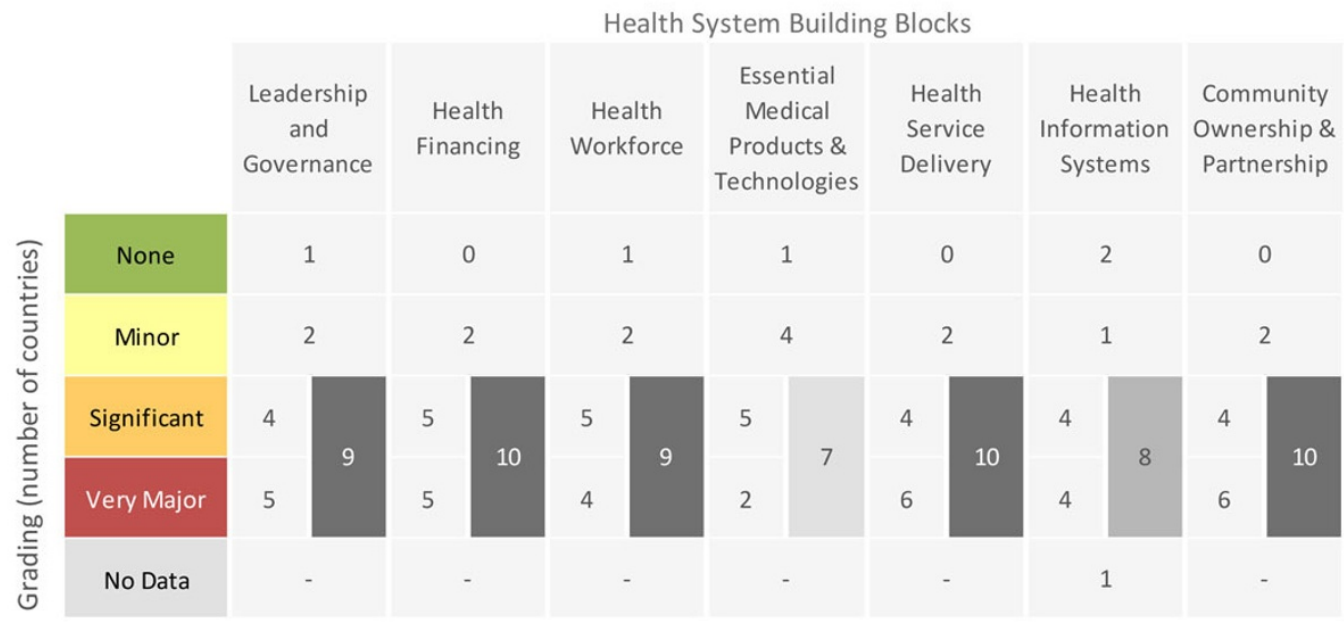

Figure 3 Individual country grading of health system bottlenecks for kangaroo mother care. Part A: Heat map showing individual country grading of health system bottlenecks for kangaroo mother care. Part B: Table showing total number of countries grading significant or major for calculating priority building blocks. DRC: Democratic Republic of the Congo.

Asia and only one of six countries in Africa (Figure 2). Ten countries reported poor availability of basic supplies for $\mathrm{KMC}$ in health facilities, particularly those required to support the feeding of LBW babies (Table 1). Procurement and supply chain issues were also mentioned.

Proposed solutions included developing a standard list and budget for equipment needed to promote $\mathrm{KMC}$ and procuring basic supplies.

\section{Health service delivery bottlenecks and solutions}

Health service delivery was rated as having significant or very major bottlenecks across 10 out of 12 countries (Figure 2). Eight countries reported that facilities did not have adequate space for the performance and monitoring of KMC. Presence of poor referral and transport systems, poor quality of KMC delivery and weak quality improvement measures were also reported (Table 1).

Solutions included conducting advocacy and creating policies to encourage investment in space for $\mathrm{KMC}$ and making KMC follow-up a part of existing postnatal services. Additionally, participants from Vietnam proposed a quality improvement solution, which involved integrating $\mathrm{KMC}$ and breastfeeding promotion into a scoring system for evaluation of health facility performance.

Health information system bottlenecks and solutions

The health information system building block was rated as having significant or very major bottlenecks across 
Table 1. Summary of bottlenecks and solution themes for scale-up of kangaroo mother care

\begin{tabular}{|c|c|c|c|c|}
\hline $\begin{array}{l}\text { Health } \\
\text { system } \\
\text { building } \\
\text { block }\end{array}$ & Subcategory & Significant bottleneck & $\begin{array}{l}\text { Number } \\
\text { of } \\
\text { countries }\end{array}$ & Solution themes \\
\hline \multirow[t]{2}{*}{$\begin{array}{l}\text { Leadership \& } \\
\text { governance }\end{array}$} & $\begin{array}{l}\text { Policy and } \\
\text { guidelines }\end{array}$ & $\begin{array}{l}\text { Absence of national KMC policies/strategies and/ } \\
\text { or creation and dissemination of service } \\
\text { guidelines to support the implementation and } \\
\text { scale-up of KMC }\end{array}$ & 10 & $\begin{array}{l}\text { - Advocacy and sensitisation } \\
\text { - Policies / include in national MCH objectives / } \\
\text { guidelines/ strengthen role of Ministry of Health }\end{array}$ \\
\hline & Awareness & Poor or no awareness of KMC by leadership & 3 & - Implementation modalities and curriculums \\
\hline \multirow[t]{3}{*}{$\begin{array}{l}\text { Health } \\
\text { financing }\end{array}$} & Funding & $\begin{array}{l}\text { Funding limited or not available for } \\
\text { implementation and scale-up }\end{array}$ & 6 & - Advocacy for increased budget/funding \\
\hline & $\begin{array}{r}\text { Out-of-pocket } \\
\text { costs }\end{array}$ & $\begin{array}{l}\text { Burden of out-of-pocket expenditures by } \\
\text { caregivers }\end{array}$ & 6 & - Development of a costed master plan \\
\hline & Policy & $\begin{array}{l}\text { Lack of integration of KMC in national costing } \\
\text { plans/policies }\end{array}$ & 2 & $\begin{array}{l}\text { - Increased donor support } \\
\text { - Insurance and/or community financing schemes }\end{array}$ \\
\hline
\end{tabular}

Health Number, Shortage of competent health workers and poor

workforce competence, distribution of properly trained personnel

distribution of authorised to provide care for LBW babies and

health workers support KMC

Training Lack of training of health workers on KMC

Mentorship and Lack of mentorship and supervision mechanisms supervision for KMC

Knowledge and Poor knowledge and awareness of health workers awareness regarding importance and utility of KMC

Attitudes Negative health worker attitudes towards KMC

Job descriptions Lack of job descriptions for health workers supporting KMC

\begin{tabular}{|c|c|c|c|c|}
\hline \multirow{2}{*}{$\begin{array}{l}\text { Essential } \\
\text { medical } \\
\text { products \& } \\
\text { technologies }\end{array}$} & Resources & $\begin{array}{l}\text { Unavailability of resources and supplies needed } \\
\text { to perform KMC }\end{array}$ & 10 & - Budget with funding for equipment \\
\hline & Procurement & $\begin{array}{l}\text { Poor procurement and supply chain logistics for } \\
\text { KMC }\end{array}$ & 2 & $\begin{array}{l}\text { - Procurement of basic supplies } \\
\text { - Standard list of equipment in facilities }\end{array}$ \\
\hline \multirow[t]{5}{*}{$\begin{array}{l}\text { Health service } \\
\text { delivery }\end{array}$} & $\begin{array}{r}\text { Physical and } \\
\text { logistical } \\
\text { constraints }\end{array}$ & $\begin{array}{l}\text { Lack of space and logistical constraints related to } \\
\text { support and monitoring of mothers/caregivers } \\
\text { performing KMC }\end{array}$ & 8 & - Investment in space \\
\hline & Quality & $\begin{array}{l}\text { Poor quality of care issues and lack of quality } \\
\text { improvement related to the implementation of } \\
\text { KMC }\end{array}$ & 4 & - KMC follow-up made a part of existing services \\
\hline & Follow-up & Lack of follow-up of KMC practice after discharge & 3 & $\begin{array}{l}\text { - Integration of KMC and breastfeeding } \\
\text { promotion }\end{array}$ \\
\hline & $\begin{array}{r}\text { Availability and } \\
\text { delivery }\end{array}$ & $\begin{array}{l}\text { Unavailability of services / disparities in delivery of } \\
\text { KMC }\end{array}$ & 2 & \\
\hline & Referral system & $\begin{array}{l}\text { Lack of referral system in place for KMC (transport } \\
\text { and access) }\end{array}$ & 1 & \\
\hline \multirow[t]{4}{*}{$\begin{array}{l}\text { Health } \\
\text { information } \\
\text { system }\end{array}$} & $\begin{array}{l}\text { Availability of } \\
\text { information }\end{array}$ & $\begin{array}{l}\text { Lack of information, records and data on } \\
\text { coverage of KMC and non-use of information } \\
\text { when available }\end{array}$ & 11 & $\begin{array}{l}\text { - Development of indicators and inclusion in } \\
\text { records }\end{array}$ \\
\hline & $\begin{array}{r}\text { Quality of } \\
\text { information }\end{array}$ & Poor quality information available on LBW babies & 2 & $\begin{array}{l}\text { - Capacity building for use of data to monitor } \\
\text { trends and improve services }\end{array}$ \\
\hline & $\begin{array}{r}\text { Knowledge and } \\
\text { awareness }\end{array}$ & $\begin{array}{l}\text { Lack of awareness and knowledge of and } \\
\text { mobilisation around KMC in the community }\end{array}$ & 10 & - Increase awareness including amongst men \\
\hline & Promotion & $\begin{array}{l}\text { Lack of proper mechanisms to promote KMC in } \\
\text { the community }\end{array}$ & 5 & $\begin{array}{l}\text { - Promotion of KMC in the community (better IEC } \\
\text { programmes and empowerment of community } \\
\text { health workers in KMC; translation of material to } \\
\text { local languages) }\end{array}$ \\
\hline $\begin{array}{l}\text { Community } \\
\text { ownership \& } \\
\text { partnership }\end{array}$ & $\begin{array}{r}\text { Socio-cultural } \\
\text { barriers }\end{array}$ & Socio-cultural barriers to the practice of KMC & 4 & $\begin{array}{l}\text { - Community empowerment and acceptance } \\
\text { (action plan to address community perception) }\end{array}$ \\
\hline
\end{tabular}

- Increasing number and capacity of health workers and creating a dedicated cadre for KMC

5 - Development and implementation of job descriptions and mentoring guidelines

$4 \quad$ - Setting up supervision and monitoring and evaluation mechanisms

3

3

- Training and capacity development




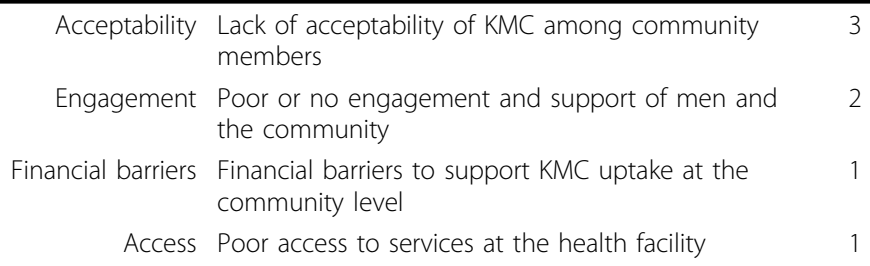

eight out of 11 countries (Nepal did not do grading), all five countries in Asia and three of six in Africa (Figure 2). It was widely recognised (11 out of 12 countries) that scale-up of KMC was hindered by the lack of coverage data in the existing health information system (Table 1). Poor quality of data on LBW and preterm birth was also mentioned.

The main proposed solutions were to improve KMC metrics by defining standard KMC indicators and incorporating them in routine data collection tools and platforms; and putting in place better reporting and clinical audits in KMC units.

\section{Community ownership and partnership bottlenecks and solutions}

Community ownership and partnership was rated as having significant or very major bottlenecks in 10 out of 12 countries (Figure 2). Ten of 12 country teams reported a lack of awareness, education and community mobilisation to increase knowledge about the benefits of KMC (Table 1). Apart from the grading, there were some differences in the specific bottlenecks between Africa and Asia. In Africa, country issues included large distances to health facilities (1 country), lack of data on acceptability of KMC in the community (1 country), existing customs of carrying babies on the back (1 country), and misconceptions including the belief that the most effective care is in an incubator (1 country). Asian countries reported that this was a new technique (1 country) and the perception that KMC was both not feasible in hot, humid environments and that privacy was a concern in its implementation ( 1 country). Country teams also mentioned the lack of information, education and communication materials in the local language and poor involvement and support of men and the general community.

Solutions proposed included better health promotion programmes, empowerment of community health workers in $\mathrm{KMC}$ and development of an action plan to address community perceptions.

\section{Discussion}

With increased attention and investment in the newborn through the ENAP [4], the Born Too Soon report [10] and a recent call for acceleration of KMC [32], KMC has been highlighted and promoted as a high impact intervention that can save lives when implemented at scale. Many countries are taking up KMC, with 33 of 55 priority countries reporting that they have a national policy for KMC in facilities for LBW/preterm babies [3]. To date, there has been limited progress for KMC implementation. Hence, there was an immediate need for a systematic, multi-country analysis of bottlenecks and solutions, and learning from countries that are further along the path to scale. The first global analysis of the barriers to KMC implementation took place in 1998 at the second international KMC workshop held in Bogota [33]; participants highlighted the need for policies, advocacy, dissemination and financial investment linked to political will. Many of these factors, as demonstrated through our findings remain important priorities. The Every Newborn Lancet Series highlighted the need for prompt and deliberate prioritisation of KMC as part of the management of small babies. Our findings highlight, support and further explore the conclusions made by Dickson and colleagues regarding regional differences between Africa and Asia for perceived challenges to the scale-up of KMC [30]. These differences are further discussed below considering country pathways to scale and examples of regional networks for implementation.

Fewer countries reported constraints with products and technologies and the health information system, reflecting the strength of KMC as a person-driven intervention. The most significant or very major bottlenecks were reported for: health financing (10 countries), community ownership and partnership (10 countries), health service delivery (10 countries), leadership and governance (9 countries) and health workforce (9 countries). Health financing and community ownership and partnership bottlenecks were significant or very major overall, in both low and high mortality contexts and in the Asia region (Figures 2, 3a and $3 \mathrm{~b}$ ). We will discuss each of these in turn.

\section{Health financing priority actions}

Financial barriers are commonly experienced in various sectors in LMICs, but newborns have been particularly neglected with respect to budgeting, and allocation of national funds and donor investments $[28,31,34]$. The main 
reported health financing bottlenecks were related to lack of policies and integration of budgets into national plans and limited funding, which are heavily influenced by leadership and governance. Additionally, concerns were expressed around the burden placed on families by out-ofpocket costs which is a general maternal, newborn and child health $(\mathrm{MNCH})$ financing concern not limited to KMC or newborns, although newborns may have been particularly missed in insurance schemes and financial protection mechanisms [28,31]. Addressing health financing gaps in $\mathrm{MNCH}$ care will help to tackle health financing barriers reported by country teams for the scale-up of KMC. This necessitates government oversight to advocate for, track and govern the allocation of funding for $\mathrm{MNCH}$ interventions, with a commitment to integrate KMC into national strategies, implementation guidelines and operational management. Payment schemes (e.g. community-based insurance and mutual health) are needed to lessen the burden of out-of-pocket expenses for families [28,30,35]. Public awareness is important to advocate for alternative financing mechanisms to address financial bottlenecks for the underserved [30].

A costed health sector plan for reproductive, maternal, newborn and child health should include KMC as part of newborn care, with a clearly linked implementation strategy adapted at national and sub-national levels. Cost-effectiveness analyses are helpful in promoting KMC and addressing bottlenecks to its uptake; for example, those related to health financing (e.g. direct costs for families and cost savings for health facilities), health service delivery (e.g. duration of hospital stay) and health workforce (e.g. staff load) [36-38]. Cost-effectiveness analyses have been undertaken in Nicaragua [39], Ethiopia [40,41] and Colombia [38] showing the cost savings of KMC versus standard care. In Nicaragua, $\mathrm{KMC}$ was found to be less expensive than standard care even without including the long-term health and economic benefits of improved cognitive abilities and reduced stunting and wasting. In Colombia, the Kangaroo Foundation developed a package for public and private insurance covering all of the costs of care for a KMC infant including follow-up for one year of corrected age; this could be useful in defining a minimal universal KMC package (Personal communication with Nathalie Charpak).

The bottlenecks around health financing are further exposed by the fact that a pathway for KMC scale-up in low-income countries, like for many other interventions, has been donor initiated and has resulted in countries being dependent on this funding. Including KMC within the Global Financing Fund for Reproductive, Maternal, Newborn and Child Health by the World Bank could be a welcome shift to a systems approach to scaling up and institutionalising KMC [42]. This donor-led entry point has been translated to institutionalisation and health sector funding in a number of countries such as Tanzania and Rwanda.

\section{Community ownership and partnership priority actions}

Respondents in the bottleneck workshops mentioned lack of community awareness of the burden of prematurity and the need for KMC as a major bottleneck. Evidence and international guidelines endorse KMC in health facilities and continuation at home post-discharge, but as yet the WHO does not recommend community-based initiation of KMC. Socio-cultural factors may hinder rapid and universal uptake of $\mathrm{KMC}$, both by communities and health workers (Figure 4). Promotion of uptake of KMC involves engaging all of the community including cultural, religious, and community leaders, enlisting support from grandparents and family members, and shifting social norms around KMC positioning and skin-to-skin contact while avoiding stigmatisation of KMC provision as a failure to bear a full-term infant or to afford incubator care [35]. Workshop participants proposed formative research and a linked plan to address community perceptions that hinder the acceptance of KMC.

In Malawi, for example, there is now wide national awareness of KMC due to a national community sensitisation campaign through radio and community groups, and community change agents (e.g. grandparents) as well as distribution of family counselling materials promoting KMC [43-45]. This multi-channel promotion may have contributed to increased commitment to the implementation of KMC in facilities, demand by health providers and mothers, and ultimately uptake of KMC [46]. The bottleneck assessment participants also underlined the important role men could play in improving the uptake of KMC as a result of their traditional role as decision-makers. They could also physically support their partners by providing intermittent KMC. The latter has been seen in Latin American and Caribbean countries (Dominican Republic, Colombia and others) and in Europe, where fathers have become regular caregivers for preterm babies [47,48] (Figure 4).

Community health and extension workers, midwives and women experienced in practising KMC can promote it during antenatal care, home visits during pregnancy and in women's groups $[35,49]$. Where a large proportion of births take place at home, community health workers could facilitate identification of small babies. For example, in rural Tanzania and Uganda, a foot-length card has been used by community health workers to identify small babies, put them skin-to-skin and refer [50,51]. Promoting the benefit of skin-to-skin care for term babies at the community level could help to normalise KMC and advance community ownership.

Although health worker support for KMC is imperative, $\mathrm{KMC}$ has the potential to change the health worker 


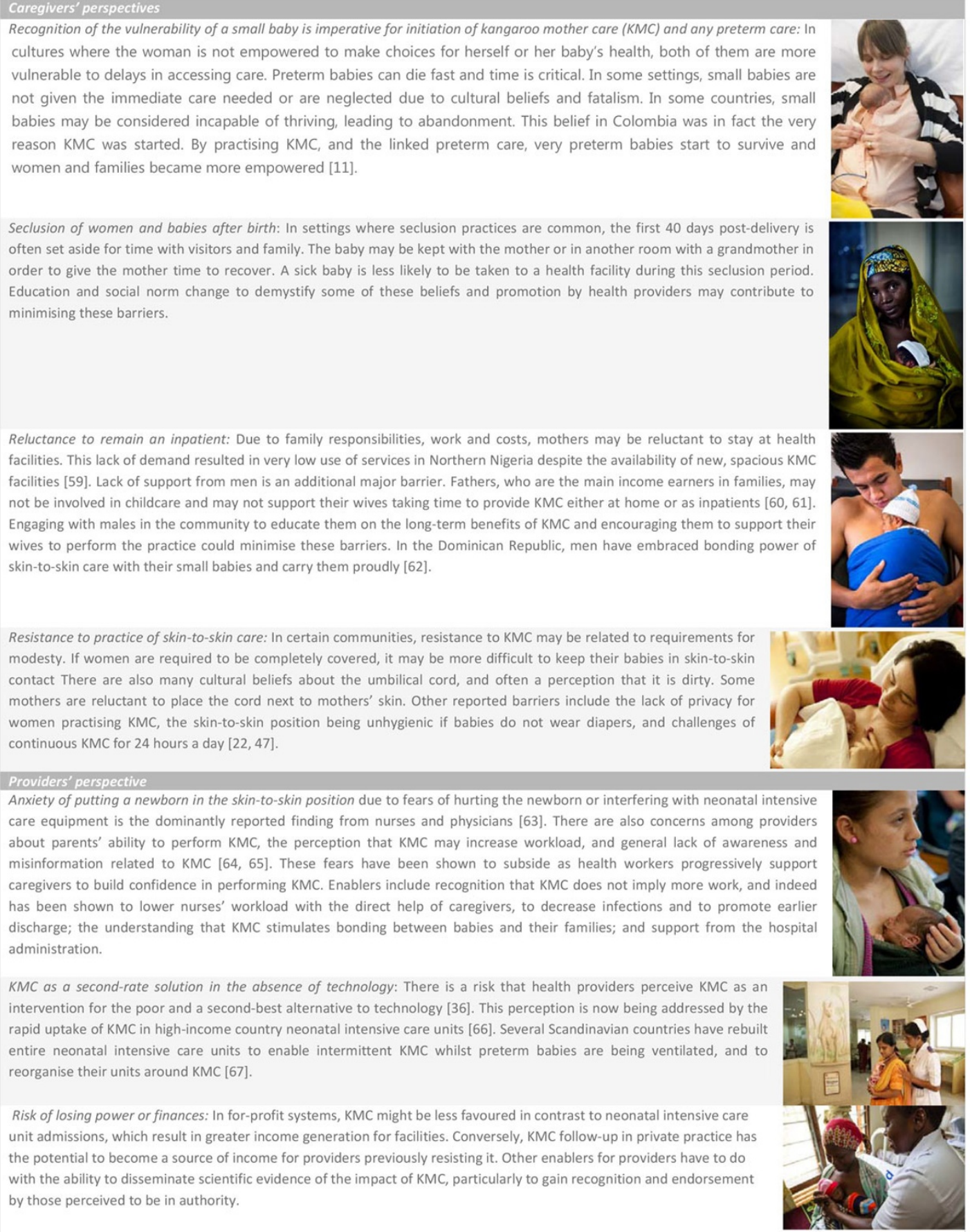

Figure 4 Overcoming socio-cultural barriers to the scale-up of kangaroo mother care and preterm care. Both caregivers and providers may have barriers to the uptake of KMC. Local context must be taken into account to understand and overcome these barriers. Based on literature and programme experience of the authorship team, we summarise some of the common barriers faced and enablers found. KMC: kangaroo mother care. Mother practicing KMC image source: Save the Children. Mother practicing KMC image source: Pep Bonet/NOOR for Save the Children. Father practicing KMC image source: Erica Pineros/Save the Children. Mother practicing KMC image source: ${ }^{\circ}$ EFCNI. Mother practicing KMC with baby with long-term oxygen treatment image source: ${ }^{\circ}$ Fundación Canguro. Mother practicing KMC with nurse by her side: Ritam Banerjee/Save the Children. Mother practicing KMC with twin babies: Jordi Matas/Save the Children 
dominated model of care by empowering mothers and families to play a crucial role in their child's treatment plan [52]. KMC bottlenecks did not differ by mortality contexts, as for most other maternal and newborn interventions, but rather by region, which suggests that cultural perceptions may play a large role in the implementation of
KMC. Community-led approaches may be more common in high-income settings where $\mathrm{KMC}$ is more frequently demanded by mothers and fathers (Figure 5). However, creating aspirations to adopt practices associated with high-income societies could potentially be utilised to stimulate greater demand in low-income settings.

\section{Initiated by an individual or small group of champions}

Kangaroo mother care (KMC) was introduced in countries at different time points since the late 1980s, mostly in the form of individual events limited to one or a few hospitals and driven by an individual or a small group of champions $[29,36,53]$. Frequently, the drivers were neonatologists, paediatricians and academics working in a teaching hospital $[14,45,54]$. A long time often elapsed before the practice was extended to other hospitals, and in some countries even after 20 years it has remained in only one. This stagnation may have been aggravated by the scepticism of other health professionals about KMC, either due to lack of information, especially preceding the availability of mortality impact data or to seeing KMC as a "poor country solution" [36].

Some of these countries, for example Ethiopia [41] and Mali [45], have recognised this limitation and are moving to wider and more institutionalised scale-up. The scale-up of KMC in Colombia is the quintessential example of a champion-driven process. The Kangaroo Foundation established two evidence-based guidelines for KMC, and focused on training other centres all over the world after only establishing two service training centres in their own country of Colombia. As a result of this strong foundation, the national Ministry of Health was able to endorse the guidelines and initiate scale-up $[20,22,68-70]$. Malawi was one of the first countries in Africa to scale up KMC [45], introduced by a champion around 2000, expanded by donors and currently supported through the government health structure $[44,71]$. With a national KMC policy and pre- and in-service training guidelines in place [43], KMC services are currently available in most hospitals in the country.

\section{Project-initiated approach}

The first expansions of KMC services to more health facilities were often linked to donor-driven time-limited projects, usually as part of a broader maternal and/or newborn care initiative. This approach was more actively practised after 2005 when countries began to pay attention to newborn deaths, and was more common in African, Asian and Latin American and Caribbean countries for example with programmes supported by Save the Children's Saving Newborn Lives programme, Maternal and Child Health Integrated Program (MCHIP) and its predecessor Access to Clinical and Community Maternal, Neonatal and Women's Health Services (ACCESS), with the Bill and Melinda Gates Foundation and the United States Agency for International Development being the major funders $[35,45]$. Although the ministries of health and other health authorities were partners in the ventures usually with a national policy and process put in place, funding was derived mostly from donors. Since about 2005, more countries started including KMC as part of their maternal, newborn and child health strategic plans [72].

\section{Health system-designed programmes with national government funding from the start}

The Istanbul Declaration calls for the acceleration of the provision of KMC services and a strengthening of the involvement of ministries of health to take responsibility for the scale-up of KMC [32].

Two examples of scale-up of KMC dating from the early 2000s are Brazil and South Africa although the entry points were champions at individual hospitals who introduced KMC in the mid-1990s, and donors or other external funding was a key part of the process. In Brazil, the health system driven scale-up of KMC was part of the Ministry of Health's drive for more humanised care for low birth weight babies, with the financial support of the Brazilian Development Bank [73, 74]. After training in the Colombian KMC Foundation, the Brazilian Ministry of Health helped to train health workers in the implementation of inpatient and outpatient KMC; however, national uptake of institutionalised services has been slow [75].

In South Africa, the entry points for health system driven KMC scale-up varied across time and by province, with sponsorship and leadership provided by champions, donors and/or a provincial health department [76-80]. Currently, the further strengthening of KMC services is driven by the district clinical specialist teams instituted by the Minister of Health and is linked with the Mother- and Baby-friendly Initiative [81-83].

\section{A combination of the above three pathways}

A number of countries (including Malawi and Rwanda) transitioned KMC from a champion based approach to a donor-led initiative linked with government to a more sustainable, integrated service within less than a decade [45]. Some such as Tanzania now have KMC funded through district health budgets.

A regional example of synergy between clinician champions, donors and ministries of health is the interagency group, the Latin American and Caribbean (LAC) Neonatal Alliance [84], created in 2005 to spearhead scale-up of KMC in 11 countries (Guatemala, Nicaragua, Honduras, El Salvador, Ecuador, Colombia, Paraguay, Peru, Bolivia, Dominican Republic and Haiti). Although most participating countries were supported by donors with approval from ministries of health, only El Salvador and Peru have adopted KMC as a norm, with government support for expansion. Countries are in various stages of implementation and some have long-standing institutional programmes. The LAC Alliance enabled the development of a KMC regional network with its own virtual community of practice to facilitate coordination of the efforts and measurements of KMC implementation, as well as the regional standardisation of the implementation approach, tools, and indicators. Although LAC countries were not included in this 12-country bottleneck analysis, they have found similar challenges, and implemented many of the solutions discussed in this paper, particularly around the need to develop and sustain local leadership.

Figure 5 Pathways from policy to implementation for kangaroo mother care. Countries have followed different pathways in introducing and expanding implementation of KMC services. Based on a review of the processes in a small number of countries in Latin America, South Asia and Africa that now have KMC services in more than half of facilities that conduct births and adapting from previous work, we have identified three entry points: champion(s), a project-based approach, and a health system-designed programme [26,30]. KMC: kangaroo mother care. LAC: Latin American and Caribbean. 


\section{Health service delivery priority actions}

KMC requires a continuum of care from facility to home and between the different levels of the health system [43]. Entry points and integration of KMC into existing services vary depending on the health systems context (Figure 1). In high mortality settings, the priority is saving lives with the efficient use of the limited availability of human and capital resources. In addition, KMC provides potential relief to busy midwifery and nursing staff, more rational use of space, and the potential for early discharge.

The goal of implementation of KMC or any other intervention is for the practice to become functional and integrated at all levels of the health system [53]. KMC services have been mainly introduced at tertiary facilities $[14,29,45,54]$ despite most facility deliveries taking place at lower levels or at home. Wherever the majority of births take place, often at district level health facilities, space designated for KMC should be prioritised, close to the labour ward and adjacent to the neonatal intensive care unit or special care unit [55]. Country teams proposed tailoring health worker curricula and service guidelines to the level of care. Specific guidelines such as those for admission and discharge criteria, detailed ward protocols (e.g. rules about visitors and rooming-in, provision of meals and use of incubators) and relevant training for health providers are all essential for effective service delivery and for ensuring consistent quality of care at multiple sites in a given country.

As complexity of care has increased and as mortality has been reduced, middle-income countries, such as Colombia, Brazil, and South Africa have demonstrated the shift to using KMC as part of special care and neonatal intensive care. A number of high-income countries have recently placed major emphasis on KMC including substantial structural investments to integrate KMC into intensive care services (Figure 1). In many of these countries, the motivation is improved outcomes such as reduced disability, and family-centred care. In middleincome countries, there has been a gradual building of multi-disciplinary teams with centres of excellence for preterm baby care, including involvement of nutritionists, physiotherapists, speech therapists and other linked medical disciplines as well as more robust follow-up systems.

In low-income settings, compliance with referral of small babies to a health facility and providing ambulatory and follow-up services after facility discharge have been identified as critical challenges [45]. Solutions could include frequent and regular follow-up, at a peripheral lower-level site with appropriate outpatient care, or in the community via home visits to track growth and promote healthy care-taking behaviours [35], with referrals to higher level facilities to manage complications [45].
Preterm babies are especially vulnerable to weaknesses in referral systems.

\section{Leadership and governance priority actions}

The bottleneck analysis results confirm the barriers related to the lack of awareness and commitment among leadership identified by Charpak and colleagues [47], which are essential for investment in a health system scale-up and especially for ongoing sustainability. Sensitising leadership at all levels (national and facility) to preterm birth care including KMC may positively influence more rapid scale-up.

The end goal of high coverage and quality of maternal and newborn care including KMC is the same, but the entry point and pathway to scale may vary [29]. The three main pathways for initiation of KMC that have been used in countries include: (1) initiation by an individual champion or small group; (2) project-based initiation; and/or (3) health system-designed programme (Figure 5). There are countries that have shifted from one to the next of these three approaches (e.g. Malawi) or have combined them (e.g. Rwanda).

\section{Health workforce priority actions}

Limited information is available on human resources required to provide KMC services at different levels of health facilities and to promote skin-to-skin care in the community. Staff qualifications may vary according to the criteria set for the commencement of continuous KMC. Where stable babies start with continuous KMC at a lower weight or gestational age, highly qualified personnel should be available at all times. Where babies are enrolled into continuous $\mathrm{KMC}$ at a higher weight or gestational age or when mothers are practising intermittent KMC, task shifting may be possible, with lowerqualified but experienced staff providing support [55]. At one major hospital in Malawi, in the absence of qualified staff, patient attendants were trained to run the KMC ward under nursing and medical supervision [56]. Supervision by a senior professional nurse or other related cadre is crucial at all times, with limited or no staff rotation given the specialisation required to care for vulnerable LBW and preterm babies [55].

One important lesson learned is incorporation of KMC and other competency based maternal and newborn care into pre-service education and not relying on high cost, time-consuming, in-service training models.

\section{Limitations}

General limitations of the bottleneck analysis tool and process, including its subjectivity, quality and length, are described in the first paper of this series [28]. The results are based on the knowledge and opinions of the individuals who completed the bottleneck analysis tool 
and may not capture all views and experiences in the country, particularly those of mothers and families.

The observed regional differences between Africa and Asia might not have been apparent had different countries been involved in the analysis. Some of the African countries (Cameroon, Malawi and Uganda) had a longer history of $\mathrm{KMC}$ implementation with more intentional scale-up support across the continent including intercountry learning visits, workshops and shared toolkits. Meanwhile in Asia some countries had a longer history (India and Vietnam), but less transferability and support across large, diverse settings [35]. However, the consistency of the grading between countries regarding the bottlenecks and the practical solutions proposed do provide valuable information for programmes.

\section{Future agenda}

Considering all the bottlenecks, experiences and strategies discussed above, a crucial step for most countries is to embed KMC in national health sector plans and define and disseminate a national KMC policy with specific service standards at each level, alongside rollout strategies that take into consideration the place of birth and needs of the community. Political commitment includes deriving and allocating adequate funds for scale-up. Finally, community awareness, mobilisation and overcoming socio-cultural barriers to normalise $\mathrm{KMC}$ are critical and require systematic, context-specific approaches. In doing so, bottlenecks to the other health system building blocks, particularly for data collection and monitoring and accountability, will need to be addressed (Figure 6). Validated indicators, especially for coverage, are a critical need and are being developed as part of the Every Newborn metrics work [57].

There are many research questions linked to this implementation agenda for KMC, particularly around context-specific solutions to the main challenges in terms of community and provider uptake, human resource innovations and novel financing strategies. Many of these are wider than $\mathrm{KMC}$ alone. In addition, improved costing data for programme planning will be key. Community initiation of $\mathrm{KMC}$ requires more rigorous testing but empowerment of women and communities and promotion of skin-to-skin care are also critical to widespread adoption of KMC.

Key messages

- The Kangaroo mother care (KMC) method is a systematic approach to the care of preterm and/or low birth weight infants; the infant is placed and held in direct and continuous skin-to-skin contact on the mother's chest in the kangaroo position. Other key components of KMC are support for exclusive and early initiation of breastfeeding and timely KMC discharge from the hospital with appropriate follow-up.

- Bottlenecks to the scale-up of KMC were reported across all seven health system building blocks. The perception of health system bottlenecks varied by region with much greater challenges for all building blocks reported by Asian countries compared to African countries.

- Overall, most countries reported significant or very major bottlenecks for health financing, community ownership and partnership and health service delivery; health financing and community ownership and partnership bottlenecks were significant or very major overall, in both low and high mortality contexts and in the Asia region. Significant bottlenecks also existed in leadership and governance and health workforce building blocks.

Key action points

- Health financing was identified as a significant or very major bottleneck with barriers relating more broadly to maternal, newborn and child health. Addressing this will require leadership from governments to integrate financing for KMC into wider health systems improvements, and to ensure financial protection.

- Community ownership and partnership was also identified as a significant or very major bottleneck. Solutions identified include working with community change agents such as grandparents or community health workers, using media and communication materials, and utilising context-specific approaches to overcome local socio-cultural barriers. There is a need to change the perception of KMC as merely possible and useful within the walls of health facility in order to drive demand and normalisation and surmount obstacles.

- Health service delivery bottlenecks included lack of space, adequate referral, delivery and follow-up of KMC and quality improvement. Solutions include designating space for KMC, ensuring continuity of service delivery beyond health facilities and tailoring health worker curricula and service guidelines to all levels of care including the community.

- Models for large scale implementation: As more countries plan to scale up KMC, we can learn from the dozen or so countries with national implementation and accelerate the process by combining approaches with individual clinical champions, donor-initiated approaches and health system implementation. However, since the coverage has been quite low, there may be a need to rethink the current models and start thinking about community-led efforts which to date have been missing. 


\section{Conclusions}

The global community is increasingly recognising the importance of saving newborn lives, and promoting a healthy start in life, particularly concentrated among babies born too soon or too small. The Every Newborn initiative is a response to national and global stakeholders' requests for coordinated, evidence-based action, and KMC is part of that plan [30,58]. Preventive interventions for preterm birth have limited impact at present. Other more complex therapeutic care for preterm babies is important but it will take more time and investment to develop equipped neonatal intensive care units and train staff to provide high-quality care. KMC can be gradually implemented as barriers are being addressed. Whilst a small number of countries in most regions (Latin America, Asia, Africa and Europe) have reached a measure of scale with $\mathrm{KMC}$, many others are now designing how to integrate and scale up within their health system contexts. Given rapid on-going progress, this paper highlights the value of countries learning from one another, and highlights how to identify and overcome context-specific challenges so that every woman who has a preterm baby needing KMC and care will be able to provide this care.

\section{Additional material}

Additional file 1: Format: PDF. Bottleneck tool questionnaire.

Additional file 2: Format: PDF. Supplementary tables, figures and literature search strategy.

\section{List of abbreviations}

ENAP: Every Newborn Action Plan, KMC: Kangaroo Mother Care; LBW: Low Birth Weight; LMIC: Low and Middle Income Countries; MNCH: Maternal, Newborn and Child Health; NMR: Neonatal Mortality Rate; WHO: World Health Organization.

\section{Competing interests}

The authors have not declared competing interests. The assessment of bottlenecks expressed during consultations reflects the perception of the technical experts and may not be national policy. The authors alone are responsible for the views expressed in this article and they do not necessarily represent the decisions, policy or views of the organisations listed, including WHO.

\section{Authors' contributions}

LV carried out the analysis with detailed inputs from KED, JEL and SGM. LV wrote the manuscript. $A B, K K, J E L, G D, B V, G M$, and $H B$ contributed to the drafting and critical revision of the manuscript. All authors read and commented on multiple drafts of the manuscript and approved the final manuscript.

\section{Acknowledgements}

This work would not have been possible without the country technical working groups and country workshop organisers and participants who undertook the bottleneck analyses. We would like to thank Helen Owen at LSHTM for her assistance with presentation of figures, and Fiorella Bianchi for her assistance with the submission process and the additional files. Finally, we would like to thank Grace Chan, Nathalie Charpak and Lucy Linley for their helpful review of this paper.

\section{Declarations}

Work for this supplement was funded by the Bill and Melinda Gates Foundation through a grant to US Fund for UNICEF (Grant ID: OPP1094117), and support from Save the Children's Saving Newborn Lives Programme. Additional funding for the bottleneck analysis was received from USAID (Grant ID: GHA-G-00-07-00007) through UNICEF.

This article has been published as part of BMC Pregnancy and Childbirth Volume 15 Supplement 2, 2015: Every Woman, Every Newborn. The full contents of the supplement are available online at http://www. biomedcentral.com/bmcpregnancychildbirth/supplements/15/S2.

\section{Authors' details}

${ }^{1}$ Innovations for Maternal, Newborn and Child Health, Concern Worldwide US, 355 Lexington Avenue, New York, NY 10017, USA. Health Section, Programme Division, UNICEF Headquarters, 3 United Nations Plaza, New York, NY 10017, USA. ${ }^{3}$ MRC Unit for Maternal and Infant Health Care Strategies, University of Pretoria, Private Bag X323, Arcadia 0007, Pretoria, South Africa. ${ }^{4}$ Saving Newborn Lives, Save the Children, 2000 L Street NW, Suite 500, Washington, DC 20036, USA. ${ }^{5}$ USAID's Maternal and Child Survival Program, 455 Massachusetts Avenue NW, Suite 1000, Washington, DC 20001, USA. ${ }^{6}$ Maternal, Adolescent, Reproductive and Child Health (MARCH) Centre, London School of Hygiene and Tropical Medicine, London, WC1E 7HT, UK. ${ }^{7}$ Department of Infectious Disease Epidemiology, London School of Hygiene and Tropical Medicine, London, WC1E 7HT, UK. ${ }^{8}$ Department of Pediatrics, Stanford University School of Medicine, Stanford, CA 94305, USA. ${ }^{9}$ School of Medicine, Pontificia Universidad Javeriana, Carrera 7 No 40-62, Bogotá, Colombia. ${ }^{10}$ Fundación Canguro, Calle 56A No 50-36 - Bloque A13, Apto 416, Pablo VI Azul, Bogotá, Colombia. ${ }^{11}$ Hospital Universitario San Ignacio, Carrera 7 No 40-62, Bogotá, Colombia. ${ }^{12}$ Department of Maternal, Newborn, Child and Adolescent Health, World Health Organization, 20 Avenue Appia, 1211 Geneva 27, Switzerland.

Published: 11 September 2015

\section{References}

1. UN-IGME: Levels \& trends in child mortality: report 2014. Estimates developed by the UN Inter-agency Group for Child Mortality Estimation. New York: United Nations Children's Fund; 2014.

2. Lawn JE, Blencowe H, Oza S, You D, Lee AC, Waiswa P, Lalli M, Bhutta Z Barros AJ, Christian P, et al: Every Newborn: progress, priorities, and potential beyond survival. Lancet 2014, 384(9938):189-205.

3. WHO, UNICEF: Countdown to 2015: fulfiling the health agenda for women and children. The 2014 report. World Health Organization: Geneva; 2014.

4. WHO, UNICEF: Every Newborn: an action plan to end preventable deaths. Geneva: World Health Organization 2014.

5. Oza S, Lawn JE, Hogan DR, Mathers C, Cousens SN: Neonatal cause-ofdeath estimates for the early and late neonatal periods for 194 countries: 2000-2013. Bull World Health Organ 2015, 93(1):19-28.

6. Blencowe H, Lee AC, Cousens S, Bahalim A, Narwal R, Zhong N, Chou D, Say L, Modi N, Katz J, et al: Preterm birth-associated neurodevelopmental impairment estimates at regional and global levels for 2010. Pediatric research 2013, 74(Suppl 1):17-34.

7. Blencowe H, Cousens S, Oestergaard MZ, Chou D, Moller AB, Narwal R, Adler A, Vera Garcia C, Rohde S, Say L, et al: National, regional, and worldwide estimates of preterm birth rates in the year 2010 with time trends since 1990 for selected countries: a systematic analysis and implications. Lancet 2012, 379(9832):2162-2172.

8. Lunze $\mathrm{K}$, Hamer DH: Thermal protection of the newborn in resourcelimited environments. J Perinatol 2012, 32(5):317-324.

9. March of Dimes, PMNCH, Save the Children, WHO: Born Too Soon: the global action report on preterm birth. World Health Organization: Geneva; Howson C, Kinney M, Lawn J 2012:

10. Conde-Agudelo A, Belizan JM, Diaz-Rossello J: Kangaroo mother care to reduce morbidity and mortality in low birthweight infants. Cochrane Database Syst Rev 2011, 3:CD002771.

11. Charpak N, Ruiz-Pelaez JG, Charpak Y: Rey-Martinez Kangaroo Mother Program: an alternative way of caring for low birth weight infants? One year mortality in a two cohort study. Pediatrics 1994, 94(6 Pt 1):804-810.

12. Charpak N, Ruiz-Pelaez JG, Figueroa de CZ, Charpak Y: Kangaroo mother versus traditional care for newborn infants $</=2000$ grams: a randomized, controlled trial. Pediatrics 1997, 100(4):682-688. 
13. Charpak N, Ruiz-Pelaez JG, Figueroa de CZ, Charpak Y: A randomized, controlled trial of kangaroo mother care: results of follow-up at 1 year of corrected age. Pediatrics 2001, 108(5):1072-1079.

14. Lawn JE, Mwansa-Kambafwile J, Barros FC, Horta BL, Cousens S: 'Kangaroo mother care' to prevent neonatal deaths due to pre-term birth complications. Int J Epidemiol 2010, 39:i144-i154.

15. Conde-Agudelo A, Diaz-Rossello JL: Kangaroo mother care to reduce morbidity and mortality in low birthweight infants. Cochrane Database Syst Rev 2014, 4:CD002771.

16. Moore ER, Anderson GC, Bergman N: Early skin-to-skin contact for mothers and their healthy newborn infants. Cochrane Database Syst Rev 2007, 3: CD003519.

17. Aghdas K, Talat K, Sepideh B: Effect of immediate and continuous mother-infant skin-to-skin contact on breastfeeding self-efficacy of primiparous women: a randomised control trial. Women and Birth 2014, 27(1):37-40.

18. Ludington-Hoe $S$, Morgan $K$, Abouelfettoh A: A clinical guideline for implementation of kangaroo care with premature infants of 30 or more weeks' postmenstrual age. Advances in Neonatal Care 2008, 8(3S):S3-S23.

19. Barker DJ: Developmental origins of chronic disease: The Richard Doll lecture. Public Health 2012, 126: 185-189.

20. Ruiz Pelaez JG, Charpak N, et al: Evidence-based clinical practice guidelines for an optimal use of the kangaroo mother method in preterm and/or low birthweight infants at birth. Bogotá: Fundación Canguro and Department of Clinical Epidemiology and Biostatistics, School of Medicine, Pontificia Universidad Javeriana 2007.

21. Charpak N, Ruiz JG, Zupan J, Cattaneo A, Figueroa Z, Tessier R, Cristo M, Anderson G, Ludington S, Mendoza S, et al: Kangaroo Mother Care: 25 years after. Acta Paediatr 2005, 94(5):514-522.

22. Ruiz-Pelaez JG, Charpak N, Cuervo LG: Kangaroo Mother Care, an example to follow from developing countries. BMJ 2004, 329(7475):1179-1181.

23. WHO: Kangaroo mother care: a practical guide. World Health Organization: Geneva, Switzerland 2003.

24. Sharma Gaurav, Mathai Matthews, Dickson Eva Kim, Weeks Andrew, Hofmeyr Justus G, Lavender Tina, Day Tina Louise, Mathews Elizabeth Jiji, Fawcus Sue, Kapeu Simen Aline, de Bernis Luc: Quality care during labour and birth: a multi-country analysis of health system bottlenecks and potential solutions. BMC Pregnancy Childbirth 2015, 15(Suppl 2):S2.

25. Liu Grace, Segrè Joel, Gülmezoglu Metin A, Mathai Matthews, Smith MJeffrey, Hermida Jorge, Kapeu Simen Aline, Barker Pierre, Jere Mercy, Moses Edward, Moxon GSarah, Dickson EKim, Lawn EJoy, Althabe Fernando, Working Group for the UN Commission of Life Saving Commodities Antenatal Corticosteroids: Antenatal corticosteroids for management of preterm birth: a multi-country analysis of health system bottlenecks and potential solutions. BMC Pregnancy Childbirth 2015, 15(Suppl 2):S3.

26. Enweronu-Laryea Christabel, Dickson EKim, Moxon GSarah, SimenKapeu Aline, Nyange Christabel, Niermeyer Susan, Bégin France, Sobel LHoward, Lee CCAnne, von Xylander Ritter Severin, Lawn EJoy: Basic newborn care and neonatal resuscitation: a multi-country analysis of health system bottlenecks and potential solutions. BMC Pregnancy Childbirth 2015, 15(Suppl 2):S4.

27. Simen-Kapeu Aline, Seale CAnna, Wall Steve, Nyange Christabel, Qazi AShamim, Moxon GSarah, Young Mark, Liu Grace, Darmstadt LGary, Dickson EKim, Lawn EJoy: Treatment of neonatal infections: a multicountry analysis of health system bottlenecks and potential solutions. BMC Pregnancy Childbirth 2015, 15(Suppl 2):S6.

28. Moxon GSarah, Lawn EJoy, Dickson EKim, Simen-Kapeu Aline, Gupta Gagan, Deorari Ashok, Singhal Nalini, New Karen, Kenner Carole, Bhutani Vinod, Kumar Rakesh, Molyneux Elizabeth, Blencowe Hannah: Inpatient care of small and sick newborns: a multi-country analysis of health system bottlenecks and potential solutions. BMC Pregnancy Childbirth 2015, 15(Suppl 2):S7.

29. Bergh AM, Charpak N, Ezeonodo A, Udani R, van Rooyen E: Education and training in the implementation of kangaroo mother care. $S$ Afr J Child Health 2012, 6(2):38-45

30. Dickson KE, Simen-Kapeu A, Kinney MV, Huicho L, Vesel L, Lackritz E, de Graft Johnson J, von Xylander S, Rafique N, Sylla M, et al: Every Newborn: health-systems bottlenecks and strategies to accelerate scale-up in countries. Lancet 2014, 384(9941):438-454.
31. Dickson EKim, Kinney VMary, Moxon GSarah, Ashton Joanne, Zaka Nabila, Simen-Kapeu Aline, Sharma Gaurav, Kerber JKate, Daelmans Bernadette, Gülmezoglu Metin A, Mathai Matthews, Nyange Christabel, Baye Martina, Lawn EJoy: Scaling up quality care for mothers and newborns around the time of birth: an overview of methods and analyses of interventionspecific bottlenecks and solutions. BMC Pregnancy Childbirth 2015, 15(Suppl 2):S1.

32. Engmann C, Wall S, Darmstadt G, Valsangkar B, Claeson M: Consensus on kangaroo mother care acceleration. Lancet 2013, 382(9907):e26-27.

33. Charpak N, de Calume ZF, Ruiz JG: "The Bogota Declaration on Kangaroo Mother Care": conclusions at the second international workshop on the method. Second International Workshop of Kangaroo Mother Care. Acta Paediatr 2000, 89(9):1137-1140.

34. WHO: The World Health Report: Health systems financing; the path to universal coverage. Geneva: World Health Organization 2010.

35. USAID, MCHIP: Kangaroo mother care implementation guide. In Washington, DC USAID, MCHIP 2012.

36. Lawn JE, Davidge R, Paul VK, von Xylander S, de Graft Johnson J, Costello A, Kinney MV, Segre J, Molyneux L: Born too soon: care for the preterm baby. Reprod Health 2013, 10(Suppl 1):S5.

37. Lima G, Quintero-Romero S, Cattaneo A: Feasibility, acceptability and cost of kangaroo mother care in Recife, Brazil. Ann Trop Paediatr 2000, 20(1):22-26.

38. Ruiz Pelaez JG: Randomized controlled trial on kangaroo mother care in Bogota: Cost-utility analysis. XI International Conference on Kangaroo Mother Care Ahmedabad, India; 2012.

39. Broughton El, Gomez I, Sanchez N, Vindell C: The cost-savings of implementing kangaroo mother care in Nicaragua. Revista panamericana de salud publica = Pan American journal of public health 2013, 34(3):176-182.

40. Cattaneo A, Davanzo R, Worku B, Surjono A, Echeverria M, Bedri A, Haksari E, Osorno L, Gudetta B, Setyowireni D, et al: Kangaroo mother care for low birthweight infants: a randomized controlled trial in different settings. Acta Paediatr 1998, 87(9):976-985.

41. Worku B, Kassie A: Kangaroo mother care: a randomized controlled trial on effectiveness of early kangaroo mother care for the low birthweight infants in Addis Ababa, Ethiopia. J Trop Pediatr 2005, 51(2):93-97.

42. Concept Note: A Global Financing Facility in Support of Evert Woman Every Child. World Bank 2014 [http://www.worldbank.org/content/dam/ Worldbank/document/HDN/Health/ConceptNote-

AGlobalFinancingFacilitySupportEveryWomanEveryChild.pdf].

43. Bergh AM, van Rooyen E, Lawn J, Zimba E, Ligowe R, Chiundu G: Retrospective evaluation of kangaroo mother care practices in Malawian hospitals, July - August 2007 (report). Lilongwe: Malawi Ministry of Health.

44. Zimba E, Kinney MV, Kachale F, Waltensperger KZ, Blencowe $H$, Colbourn T, George J, Mwansambo C, Joshua M, Chanza H, et al: Newborn survival in Malawi: a decade of change and future implications. Health policy and planning 2012, 27(Suppl 3):iii88-103.

45. Bergh AM, Kerber K, Abwao S, de-Graft Johnson J, Aliganyira P, Davy K, Gamache N, Kante M, Ligowe R, Luhanga R, et al: Implementing facilitybased kangaroo mother care services: lessons from a multi-country study in Africa. BMC health services research 2014, 14:293.

46. Van Zyl M: The Ekwendeni Agogo Approach: Grandparents as agents of change for newborn survival. Save the Children ; 2010 [http://www. healthynewbornnetwork.org/sites/default/files/resources/Ekwendeni\% 20Agogo\%20approach.pdf].

47. Charpak N, Ruiz-Pelaez JG: Resistance to implementing Kangaroo Mother Care in developing countries, and proposed solutions. Acta Paediatr 2006, 95(5):529-534.

48. USAID, MCHIP: MCHIP Dominican Republic End-of-Project Report. 2014.

49. Lincetto O, Nazir Al, Cattaneo A: Kangaroo mother care with limited resources. J Trop Pediatr 2000, 46(5):293-295.

50. Marchant T, Penfold S, Mkumbo E, Shamba D, Jaribu J, Manzi F, Schellenberg J: The reliability of a newborn foot length measurement tool used by community volunteers to identify low birth weight or premature babies born at home in southern Tanzania. BMC Public Health 2014, 14:859.

51. Nabiwemba E, Marchant T, Namazzi G, Kadobera D, Waiswa P: Identifying high-risk babies born in the community using foot length measurement at birth in Uganda. Child: care, health and development 2013, 39(1):20-26. 
52. Nyqvist KH, Anderson GC, Bergman N, Cattaneo A, Charpak N, Davanzo R, Ewald U, Ludington-Hoe S, Mendoza S, Pallas-Allonso C, et al: State of the art and recommendations. Kangaroo mother care: application in a hightech environment. Acta Paediatr 2010, 99(6):812-819.

53. Bergh AM, Pattinson RC: Development of a conceptual tool for the implementation of kangaroo mother care. Acta Paediatr 2003, 92(6):709-714

54. Victora CG, Rubens CE: Global report on preterm birth and stillbirth (4 of 7): delivery of interventions. BMC Pregnancy Childbirth 2010, 10(Suppl 1):S4.

55. Bergh AM: Implementation workbook for kangaroo mother care. Pretoria: Medical Research Council Research Unit for Maternal and Infant Health Care Strategies 2002.

56. Blencowe $H$, Kerac M, Molyneux E: Safety, effectiveness and barriers to follow-up using an 'early discharge' Kangaroo Care policy in a resource poor setting. J Trop Pediatr 2009, 55(4):244-248.

57. Moxon GSarah, Ruysen Harriet, Kerber JKate, Amouzou Agbessi, Fournier Suzanne, Grove John, Moran CAllisyn, Vaz MELara, Blencowe Hannah, Conroy Niall, Gülmezoglu Metin A, Vogel PJoshua, Rawlins Barbara, Sayed Rubayet, Hill Kathleen, Vivio Donna, Qazi Shamim, Sitrin Deborah, Seale CAnna, Wall Steve, Jacobs Troy, Ruiz Peláez Gabriel Juan, Guenther Tanya, Coffey SPatricia, Dawson Penny, Marchant Tanya, Waiswa Peter, Deorari Ashok, Enweronu-Laryea Christabel, Arifeen El Shams, Lee CCAnne, Mathai Matthews, Lawn EJoy: Count every newborn; a measurement improvement roadmap for coverage data. BMC Pregnancy Childbirth 2015, 15(S2):S8.

58. Mason E, McDougall L, Lawn JE, Gupta A, Claeson M, Pillay Y, Presern C, Lukong MB, Mann G, Wijnroks $M$, et al: From evidence to action to deliver a healthy start for the next generation. Lancet 2014, 384(9941):455-467.

59. Kerber K, Williams A, Aboda A, Masha R, Mado S: Review of Kangaroo Mother Care Implementation in PRRINN-MNCH States. Abuja, Nigeria: PRRINN-MNCH. 2011. 2011 [http://www.healthynewbornnetwork.org/ resource/review-kangaroo-mother-care-implementation-prrinn-mnch-states].

60. Enterria A: India from Within. Guide to India's History, Religion, Arts, Culture, and Society. Varanasi India: Indica Books; 2010.

61. Sriram R: Evidence of change and continuity in fathering: The case of Western India. Marriage Fam Rev 2011, 47(8):625-647.

62. de Graft Johnson J: Giving Thanks for all Fathers who actively care for their children.[http://www.mchip.net/node/1102].

63. ElGabbas NM, Abul-Fadl AMAM, Abul-Fotouh U, El-Mahdy MH: Acceptance of kangaroo mother care by neonatal intensive care staff in two countries in the eastern mediterranean region. Breastfeed Med 2001, 6:56.

64. Chia P, Sellick K, Gan S: The attitudes and practices of neonatal nurses in the use of kangaroo care. The Australian J of Adv Nurs : a quarterly publication of the Royal Australian Nursing Federation 2006, 23(4):20-27.

65. Engler AJ, Ludington-Hoe SM, Cusson RM, Adams R, Bahnsen M, Brumbaugh $E$, et al: Kangaroo care: national survey of practice, knowledge, barriers, and perceptions. MCN Am Journal Maternal Child Nurs 2002, 27(3):146-153.

66. Pallas-Alonso CR, Losacco V, Maraschini A, Greisen G, Pierrat V, Warren I, et al: Parental involvement and kangaroo care in European neonatal intensive care units: a policy survey in eight countries. Pediatr Crit Care 2012, 13(5):568-577.

67. Strand H, Blomqvist $Y T$, Gradin M, Nyqvist KH: Kangaroo mother care in the neonatal intensive care unit: staff attitudes and beliefs and opportunities for parents. Acta Paediatr 2014, 103(4):373-378.

68. Charpak N, Figuero Z: Kangaroo mother care practical rules. Kangaroo Foundation. Bogota, Colombia.[http://fundacioncanguro.co/KMCT/en]

69. Charpak N, Ruiz Pelaez JG: Kangaroo Mother Care: past, present and future. Current Women's Health Reviews 2011, 7(3):227-231.

70. Kangaroo Mother Care Learning Portal. Lineamientos Tecnicos para la Implementacion de Programas Canguro en Colombia (Technical Guidelines for the Implementation of KMC Programs in Colombia). [http://www.minsalud.gov.co/salud/Documents/Observatorio Talento Humano en Salud/LIBRO_MADRE_CANGURO_APROBADO12.pdf].

71. USAID. Save the Children: Malawi newborn health program final evaluation report. National level - expanded impact project. 2011 [http:// pdf.usaid.gov/pdf_docs/PDACN614.pdf].

72. Moran AC, Kerber K, Pfitzer A, Morrissey CS, Marsh DR, Oot DA, et al: Benchmarks to measure readiness to integrate and scale up newborn survival interventions. Health Policy Plan 2012, 27(Suppl 3):ii29-ii39.
73. Gomez HM: Kangaroo mother care. English version. 2000 [http://www. bndes.gov.br/SiteBNDES/export/sites/default/bndes_en/Galerias/Download/ studies/KangarooMother.pdf].

74. Lamy Filho F, Silva AA, Lamy ZC, Gomes MA, Moreira ME: Evaluation of the neonatal outcomes of the kangaroo mother method in Brazil. Jornal de Pediatria 2008, 84(5):428-435.

75. Gontijo TL, Meireles AL, Malta DC, Proietti FA, Xavier CC: Evaluation of implementation of humanized care to low weight newborns - the Kangaroo Method. Jornal de Pediatria 2010, 86(1):33-39.

76. Mzolo N, Mashao L, Malan A, Robertson B: The implementation of "The Limpopo Initiative for Newborn Care" (LINC). Twenty-third Priorities in Perinatal Care Conference Proceedings 2004.

77. Pattinson R, Arsalo I, Bergh AM, Malan A, Patrick M, Phillips N: Implementation of kangaroo mother care: a randomized trial of two outreach strategies. Acta Paediatrica 2005, 97(4):924-927.

78. Bergh AM, Van Rooyen E, Pattinson R: 'On-site' versus 'off-site' facilitation: a randomised trial of outreach strategies for scaling up kangaroo mother care. Human Resources for Health 2008, 6(13).

79. Kangaroo Mother Care Provincial Task Team: Kangaroo mother care (KMC) policy and guidelines for the Western Cape Province. Cape Town: Western Cape Department of Health 2002.

80. Feucht U: Keeping children alive and healthy in South Africa - how do we reach this goal? Perspectives from a paediatrician in a District Clinical Specialist Team. S Afr J Child Health 2013, 7(4):124-126.

81. Ministerial Task Team: District Clinical Specialist Teams in South Africa: Ministerial Task Team Report to the Honourable Minister of Health, Dr Aaron Motsoaledi. 2012 [http://rmchsa.org/wp-content/resources/ resources_by_type/DistrictLevelResources/ MinisterialTTReport_DCSTInSouthAfrica.pdf].

82. Pattinson B, Rhoda N, Pillay Y, Moodley J, Velaphi S, et al: Guidelines for district clinical specialist teams for improving maternal \& neonatal health services in South Africa. 2013, Available from http://www.rmchsa. org/wp-content/resources/resources_by_type/DistrictLevelResources/ Guidelines_DCST_ImprovingMNCH_Feb2013.PDF.

83. Editorial Office: The Tshwane declaration of support for breastfeeding in South Africa. S Afr J Clin Nutr 2011, 24(4):214.

84. Latin American and Caribbean Neonatal Health Alliance.: Latin American and Caribbean Neonatal Health Alliance., Available from http://www. alianzaneonatal.org/eng/.

doi:10.1186/1471-2393-15-S2-S5

Cite this article as: Vesel et al: Kangaroo mother care: a multi-country analysis of health system bottlenecks and potential solutions. BMC Pregnancy and Childbirth 2015 15(Suppl 2):S5.

\section{Submit your next manuscript to BioMed Central and take full advantage of:}

- Convenient online submission

- Thorough peer review

- No space constraints or color figure charges

- Immediate publication on acceptance

- Inclusion in PubMed, CAS, Scopus and Google Scholar

- Research which is freely available for redistribution

Submit your manuscript at www.biomedcentral.com/submit
C Biomed Central 